\title{
Achieving Competencies with Grammar School Students through Utilisation of Seleceted Didactical Principles - Case Study of Geographic features of Europe
}

\author{
Ljubica Ivanović Bibić ${ }^{A *}$, Smiljana Đukičin ${ }^{A}$, Tin Lukić ${ }^{A}$, Đurđa MiljkovićA ${ }^{A}$ Jelena MilankovićA, \\ Snežana Babić Kekez ${ }^{B}$, Anđelija Ivkov Džigurski ${ }^{A}$, Zorica Dubovina ${ }^{C}$ \\ Received: June 17, 2015 | Revised: September 27, 2015 | Accepted: October 25, 2015
}

\begin{abstract}
The aim of this research was to ascertain the competencies of grammar school students who learn geographic features of Europe by applying selected didactical principles. The research included and grade students of "Laza Kostić" Grammar School in Novi Sad (North Serbia). Selected classess were divided into two groups of students. The experimental group teaching was performed through traditionally lecturebased teaching in the classroom with the main usage of principles of intuition and science. The control group learned through group form of teaching with the main usage of principles of interesting and attractiveness and conscious activities of students. A questionnaire containing 15 statements was used while teaching the experimental lessons. This questionnaire (based on the Likert-type 5 point scale) has been drawn up and it included a survey where students evaluated motivation and participation in the process of teaching geography or activities and learning/acquiring certain geographic content using selected didactic principles, forms, methods and tools. There was a test, which consisted of 9 questions of different levels of cognitive domains of learning - knowledge, skills and abilities. In order to determine whether there is a correlation between self-evaluation of the level of motivation, participation and learning, the self-evaluation of the level of motivation, participation and the knowledge test between the experimental and control group, Pearson correlation coefficient was determined. The results show that the level of students' reproductive knowledge remains the same in research-based traditional and modern teaching, but the problem-solving skills and abilities related to selected geographical features improved within experimental group of students.
\end{abstract}

Key words: geography, students'competencies, lecturebased teaching, didactical principles, grammar school

\section{Introduction}

Lessons carried out in Serbian schools are assessed as lectures (traditional), where students are seen more as objects rather than subjects of educational work, they are more passive listeners than active agents in the process of their own development, therefore there is a general attitude among the educational public on the need to introduce changes in education. In this sense, there is a strong emphasis on the need to change the passive forms of learning into active forms, where teaching would be tailored to suit each student and to encourage the development of individuals. Active teaching is a didactic-methodical model of organising educational work which has been conceived on the natural tendency of children to explore the world around them on their own (Ivić, et al., 2001a; Ivkov,

\footnotetext{
A University of Novi Sad, Faculty of Sciences, Department of Geography, Tourism and Hotel Management, Trg Dositeja Obradovića 3, 21000 Novi Sad, Serbia

B University of Novi Sad, Faculty of Sciences, Department for Chemistry, Biochemistry and Environmental Protection, Trg Dositeja Obradovića 3, 21000 Novi Sad, Serbia

c Laza Kostić Grammar School, Laze Lazarevića 1, 21000 Novi Sad, Serbia
} 
2003; Marić, Krunić, 2003; Scheyvens, et al., 2008; Babić-Kekez, Tasić, 2012; Anderson, 2013).

Didactic principles have multiple impact on the teaching process. They contain a normative, regulatory, correlating and integrating component of the teaching process. Didactic principles are affected by socio-historical development (Tracana, et al., 2008; Marius-Costel, 2010; Dubljanin, 2010; Romelić, Ivanović, 2011). There are variation in determining their number and there are different classifications, however, educators agree on the following: the principles are a system that includes education of an individual as a whole, the principles make up a whole, and each of them is applied in different and concrete educational situations (Romelić, 2004; Hamann, 2007; Ivanović, Ivkov, 2007; Yasar, Seremet, 2007; Frumos, 2008; Romelić, Ivanović, 2011; Babić-Kekez, Tasić, 2012).

This paper presents the analysis of achieving competences in 2nd grade grammar school students through selected didactic principles while teaching social and geographical features of some parts of the world (Europe). Experimental lessons have been held in four 2nd grade classes of "Laza Kostić" Grammar School in Novi Sad.

The obtained results are derived from teaching experimental lessons, provided that the first two lessons were held in a traditional manner with the emphasis on the principles of intuition and science, the use of frontal method of teaching and monologue-dialogue methods, while the other two lessons have been realised through active teaching, placing emphasis on didactic principles of interesting and attractiveness and on conscious activities of students, with the use of group work, dialogue and illustrative-demonstrative methods.

After teaching all the lessons (in both experimental and control groups), students anonymously responded to a survey which aimed to examine their attitudes in terms of motivation, participation, activity and learning/achieving certain geography content while teaching geography using selected didactic principles, forms, methods and tools. On the other hand, the knowledge assessment aimed to examine the competence of students after teaching the new material, wherein the control questions were divided into three segments: skills, knowledge and abilities.

\section{Application of didactic principles, forms and methods in teaching experimental lessons}

While teaching the experimental lessons in "Laza Kostic" Grammar School, the focus has been on four didactic principles: intuition, science, interesting and attractiveness and the principle of concious activities of students. The first two mentioned principles are mainly used in the first two lessons, where the traditional way of teaching has been applied within the experimental group.

\section{Research process and organisation}

The principle of intuition can be seen as the most specific and most essential principle in teaching geography, although the principles cannot be categorised according to importance. The principle of intuition contributes in such a way that students use sensory perception to observe and experience the objective reality studied in a particular subject. Intuition is a didactic imperative, and it is accomplished by observing the geographic objects, phenomena and processes in geographic space. Observation may be direct (e.g. an excursion) and indirect (with teaching aids) (Romelić, Ivanović, 2011).

During the first two lessons, the didactic principle of intuition was supposed to be represented as much as possible. Using a prepared PowerPoint presentation and transparency, several thematic maps have been presented in a simple, vivid and accurate manner showing the boundaries, natural and geographical features and political division of Europe. In addition, activation of students has been conducted by inviting them to show specific geographic terms on the map, as well as to fill in outline maps with information related to the teaching unit "Geographical features of Europe, position, size, expansion, natural features, political division". The advantage of this principle was seen in the use of a computer, a projector, an overhead projector and additional technical resources which facilitate and improve the teaching of geography in a simple and efficient way (e.g. IvkovDžigurski, et al., 2009).

The second principle which has been highlighted in the first two lessons is the principle of science. The scientific basis of this principle is that by applying it in practice, logical and abstract thinking is being achieved. Therefore students form a scientific view of the world and a critical approach to everything that is dogmatic in character. The scientific view of the world can only be achieved by adopting the knowledge that is scientifically validated. It is necessary to insist on scientific truth without interference of personal and/or political beliefs (Romelić, Ivanović, 2011). The teacher cannot bring to the fore any personal preferences and beliefs. He/She is primarily an educator and lecturer who has to present the subject to the students, to teach them, and to enable them to acquire knowledge independently.

The frontal method was used in the first two lessons. It is the most common and basic method used in the classroom. It represents teaching the whole class at the same time. It is easy and practical to use (Romelić, 
2004; Đukičin, et al., 2014). The work is done with the whole class, the same tasks are given, the same teaching methods and teaching aids are used (Ivkov, 2002). By using this method, the teacher is the one who leads the teaching process. The student is in the role of the listener. What is positive about this method is the fact that a large amount of information can be spread rapidly (Romelić, 2004).

The principle of interesting and attractiveness was in the forefront during the teaching of the other two lessons. The essence of this principle is reflected in the fact that teaching should be organised in such a way that it is interesting and attractive, and that arouses curiosity and motivation in students. Attractiveness of content implies the way in which it is presented, and the interestingness refers to the interesting/uninteresting parts of the content itself. Assuming that the teaching and presenting of the educational content is more interesting and attractive, the knowledge gained in this way will be long-term and more effective. An important factor in teaching is the teacher himself/herself, whose skills and creativity influence the success of teaching. The basic idea of this principle is to overcome patterns and monotony in teaching (Romelić, Ivanović, 2011). The teacher should not define certain geographical contents as uninteresting at the very beginning (Živković, Jovanović, 2008).

Instead of the prevailing frontal method, the traditional lesson, a change in the teaching method has been achieved, mainly by group work, where the students met with a different approach to teaching about the "Population and culture of European nations". There's has been a change in pace and rhythm, a deviation from the characteristic pattern. Applying this principle included the use of modern teaching aids (computer, projector, digital geographic map), methods (dialogic and illustrative-demonstrative) and forms of work (group).

The principle of conscious activities of students has been realised through independent students' work. The basic premise of this principle is that the students understand, implement and permanently adopt certain knowledge, acquiring it through their own intellectual effort. In modern teaching, emphasis is on the student and his dominant activity (especially thought activity) during the acquisition of new knowledge. Simply put the teacher does not serve knowledge to students, they acquire it only through discovery. Problem-solving situations are being put before of them. In this way, students develop permanent working habits, become independent, which is an essential prerequisite for lifelong self-education especially in times of great scientific and technological inventions (Romelić, Ivanovic, 2011).

During the application of this didactic principle the students have been divided into groups, where each working group had the task to learn and present in a few sentences a certain part of the teaching material within the unit that was being done in this lesson. By using this form of work students independently gained certain knowledge, studied independently, the teacher assumed the role of the coordinator, with the main task of making the material accessible to students via PowerPoint presentation, along with providing certain clarifications and highlighting the most important segments of the teaching unit.

When it comes to teaching methods, monologue, dialogue and illustrative-demonstrative methods were applied. In the first two lessons which had the characteristics of traditional teaching, monological and dialogical methods were mostly applied, but the illustrative-demonstrative methods were also used. During group work, which took place in the second two lessons, the lesson on population and culture of the people of Europe was being thought, and therefore the dialogue and illustrative-demonstrative methods were used.

Teaching aids being used are divided into obvious teaching aids and additional technical resources (Ivkov, 2002; Romelić, 2004). During this research and performing experimental classes the following teaching aids have been used: Geography textbook for the 2nd grade of high school by the authors V. Kovačević and B. Mladenović Kljajić (2014), geographical map of Europe, outline maps, pictures, overhead projector and a computer with a video projector.

The computer with the projector was a great help while teaching these experimental classes. It is important to note that the use of computers and projectors significantly contributed to highlighting the didactic principle of intuition and of interesting and attractiveness Usage of different computer programs allows clear illustration of geographic content. By using visual stimulation, students become more familiar with the geographic area, create correct ideas about it, understand geographic relationships, phenomena and processes (Fletcher, 2005; Ivkov-Džigurski, et al., 2009).

\section{Methods and data}

A questionnaire was used while teaching the experimental lessons. It consisted of two parts, in order to examine the proposed hypotheses of research:

1. $H_{1}$ : Application of selected didactic principles, forms and methods while processing certain teaching units gives positive results in terms of acquisition of knowledge, skills and abilities in students.

2. $H_{2}$ : Application of selected didactic principles, forms and methods while processing certain teaching units contributes to better motivation in terms 
of participation, activities and learning/acquiring certain geographic content by students.

For research purposes, the previously mentioned questionnaire has been drawn up and it included a survey of 15 claims where students evaluated motivation and participation in the process of teaching geography or activities and learning/acquiring certain geographic content using selected didactic principles, forms, methods and tools. There was also a test, which consisted of 9 questions of different levels of cognitive domains of learning - knowledge, skills and abilities. The questionnaire, as well as the test of acquired students' competences after teaching the new material were designed according to the model outlined by Borić and Škugor (2012).

The first part of the questionnaire consists of questions related to the attitudes of students in terms of motivation and participation in the process of teaching geography using selected didactic principles, forms, methods and tools and activities and learning/ acquiring certain geographic content by using selected didactic principles, forms, methods and tools.

The second part represents the examination of students' competencies after teaching the new material where acquisition of knowledge, skills and student's abilities is being determined.

The Likert scale was used for testing the first part of the questionnaire which was closed-ended. It provides participants with the task to express their level of agreement or disagreement for each individual claim, in principle, on a five-point scale as follows: 1- Strongly Disagree; 2- Disagree; 3- Undecided; 4- Agree; 5Strongly Agree (Likert, 1932).

Classes where teaching was carried out traditionally were used as an experimental group, while classes where teaching was carried out by applying modern methods and forms of work were used as a control group. During the processing of the questionnaire the software package MS Office Excel was used for computing the mean and percentage values and calculating the correlation coefficient.

Pedagogical and methodological researches reveal and conclude pedagogical phenomena, and it is very important to determine the connection between them (correlation). Depending on the nature of the pedagogical experiment the most commonly used are Pearson correlation coefficient and Spearman's rank correlation. Pearson correlation coefficient was used in this paper.

Pearson correlation coefficient is used in cases where there is a linear connection and continuous normal distribution between the model variables. The value of the Pearson correlation coefficient (r) ranges from +1 (a perfect positive correlation) to -1 (per- fect negative correlation). The sign preceding the coefficient indicates the direction of the correlation - whether it is positive or negative, however, it does not point out the strength of the correlation. Pearson's correlation coefficient is a measure of linear dependence of one variable from another (Turjačanin, et al., 2006; Stojkovic, 2008).

For calculating the Pearson correlation coefficient, there should be two sets of data. The pattern that is used is:

$$
r_{x y}=\frac{N \sum X Y-\left(\sum X\right) \cdot\left(\sum Y\right)}{\sqrt{\left[\sum X^{2}-\left(\sum X\right)^{2}\right]\left[N \sum Y^{2}-\left(\sum Y\right)^{2}\right]}}
$$

Where:

$r$ - is the symbol for Pearson correlation coefficient,

$N$ - is number of cases,

$\Sigma X Y$ - sum of products obtained by multiplying the

data from columns $X$ and $Y$ from each row,

$\Sigma X$ - sum of data from the variable $\mathrm{X}$,

$\Sigma X$ - sum of data from the variable $\mathrm{Y}$,

$\Sigma X^{2}$ - sum of data from the variable $X$ squared,

$\Sigma Y^{2}$ - sum of data from the variable $Y$ squared,

Interpretation of values can be carried out on the basis of the value of the Pearson coefficient $(r)$ :

$0.00-0.20$ - slight correlation

$0.20-0.40-$ low correlation,

$0.40-0.70-$ moderate correlation,

$0.70-0.90-$ high correlation,

$0.90-1.00$ - very high correlation (Stojković, 2008).

\section{Results and discussion}

The research was carried out through the realisation of lessons in a traditional and modern way. During the traditional experimental lessons, the number of students was 50, while during the realisation of modern experimental lessons, there were 52 students.

During the last 10 minutes of the lesson, every student was supposed to complete a survey, as well as a test for examining acquired competencies after both lessons.

The survey consisted of two parts:

1. Self-evaluation of students' motivation and participation in the process of geography lessons by application of selected didactic principles, forms, means and methods;

2. Self-evaluation of students regarding activities and learning/acquiring specific geographical contents by application of selected didactic principles, forms, means and methods.

After processed results of the first part of the survey, which consists of a questionnaire for examining motivational attitudes and students' participation in the 


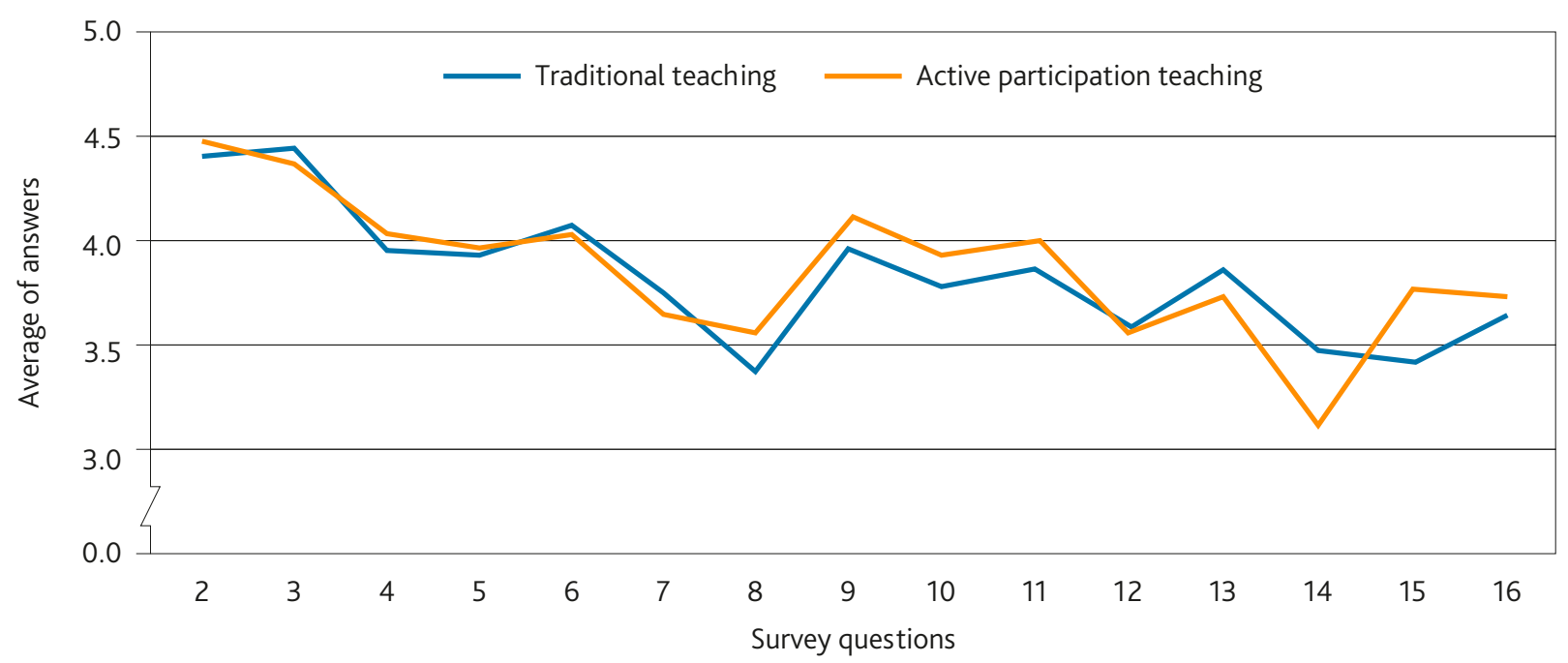

Figure 1. Comparative view of survey answers

process of geography lessons, average values were obtained with the Likert scale during the traditional and modern teaching method, which will be presented in the following text.

By analysing the average of answers from the chart, it can be stated that students prefer when the teacher organises the lesson in an interesting way. As for the traditional method, a small number of students stated that they are not pleased with the level of activities, while regarding the modern method, a small number of students stated that they prefer lessons where active participation is not necessary.

\section{Test results for examining the level of cognitive domain of learning}

After the survey had been carried out, students completed a test for examining acquired competencies after both experimental lessons.

Test for examining the level of cognitive domain of learning consisted of three parts:

1. Knowledge (3 questions)

2. Skills (3 questions)

3. Abilities (3 questions)

In the following table and charts, there are test results for the material covered in lessons which were carried out in a traditional way, with the frontal method and emphasising didactic principle of intuition and science.

Most of students' correct answers were given to questions regarding knowledge acquisition. The first question in the test was: As it is situated between large continents of Africa, Asia and America, the geographical position of Europe is characterised as being (circle the correct answer):

a) unfavourable b) favourable
The percentage of correct answers to the first question was $92.6 \%$. The smallest number of students' correct answers was to questions regarding skills acquisition. Only $14.8 \%$ of students knew the correct answer to the question 6. Question 6 was: Regarding relief, Europe is mostly a mountainous/lowland continent (circle the correct answer), because $80 \%$ of its territory is lower/higher (circle the correct answer) than 500 meters above sea level.

The question all of the students answered correctly was question 8 , referring to the abilities segment. Question 8 was: The Mediterranean Sea is (circle the correct answer):

a) a border sea b) an intercontinental sea c) an inter-island sea

The percentage of correct answers according to acquired knowledge, skills and abilities is shown in Table 1.

Table 1. Percentage of acquired knowledge, skills and abilities for frontal method

\begin{tabular}{|l|c|}
\hline Acquired & Percentage of correct answers \\
\hline KNOWLEDGE & $72.8 \%$ \\
\hline SKILLS & $43.2 \%$ \\
\hline ABILITIES & $55.6 \%$ \\
\hline
\end{tabular}

According to the results shown, it is noted that students acquired knowledge ( $72.8 \%$ ) best, and skills least (43.2\%).

When all results obtained on the test for examining students' competencies are considered, it is concluded that students successfully acquired knowledge and abilities, but achieved somewhat poorer result in regards to skills. This would mean that application of didactic principles of intuition and scholarly princi- 

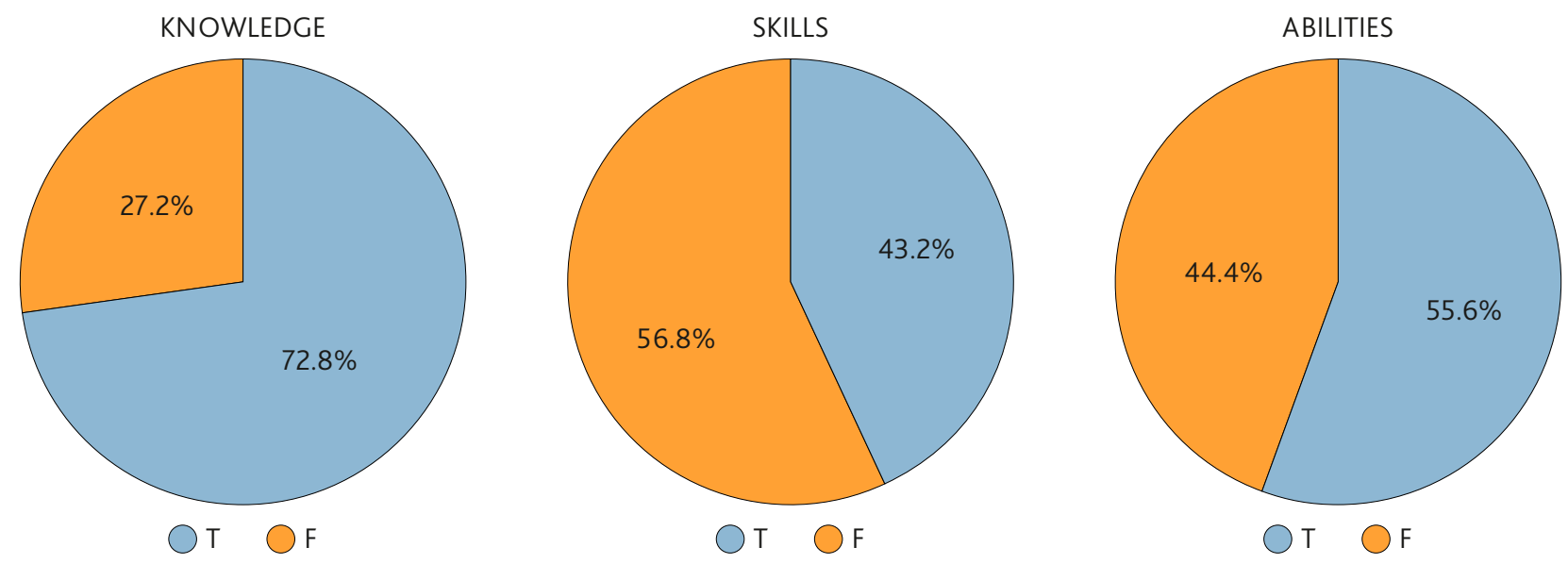

Figures 2, 3 and 4. Graphical view of acquired knowledge, abilities and skills with correct and incorrect answers when using the traditional method

ple was successfully implemented during the experimental lessons.

In the following table and charts, we can see test results of the material taught in classes when using active participation, group work and emphasising didactic principles of interesting and attractiveness and conscious activities of students.

Most students gave the correct answers to question 9, which refers to abilities acquisition, and which was: The name Europe comes from an Assyrian word "ereb" which means (circle the correct answer):

\section{a) east b) sunset/west c) rolling waves}

The percentage of correct answers was $96.0 \%$ The smallest number of correct answers was to question 4, which refers to skills acquisition, and question 8 , which refers to abilities acquisition. The percentage of correct answers to these questions was $24.0 \%$. Question 4 was: The political map of Europe was frequently changed during the course of history, especially in the oth century (circle the correct statement): a) no b) yes.
Question 8 was: The Mediterranean Sea is (circle the correct answer):
a) a border sea
b) an intercontinental sea
c) an in- ter-island sea

The percentage of correct answers according to acquired knowledge, skills and abilities is shown in Table 2.

Table 2. Percentage of acquired knowledge, skills and abilities during group work

\begin{tabular}{|l|c|}
\hline Acquired & Percentage of correct answers \\
\hline KNOWLEDGE & $73.3 \%$ \\
\hline SKILLS & $34.7 \%$ \\
\hline ABILITIES & $53.3 \%$ \\
\hline
\end{tabular}

According to this research (test), students acquired knowledge (73.3\%) and abilities (53.3\%) best, while achieving somewhat weaker results in skills acquisition (34.7\%). The obtained results can also be presented graphically, which will be shown on the following charts.
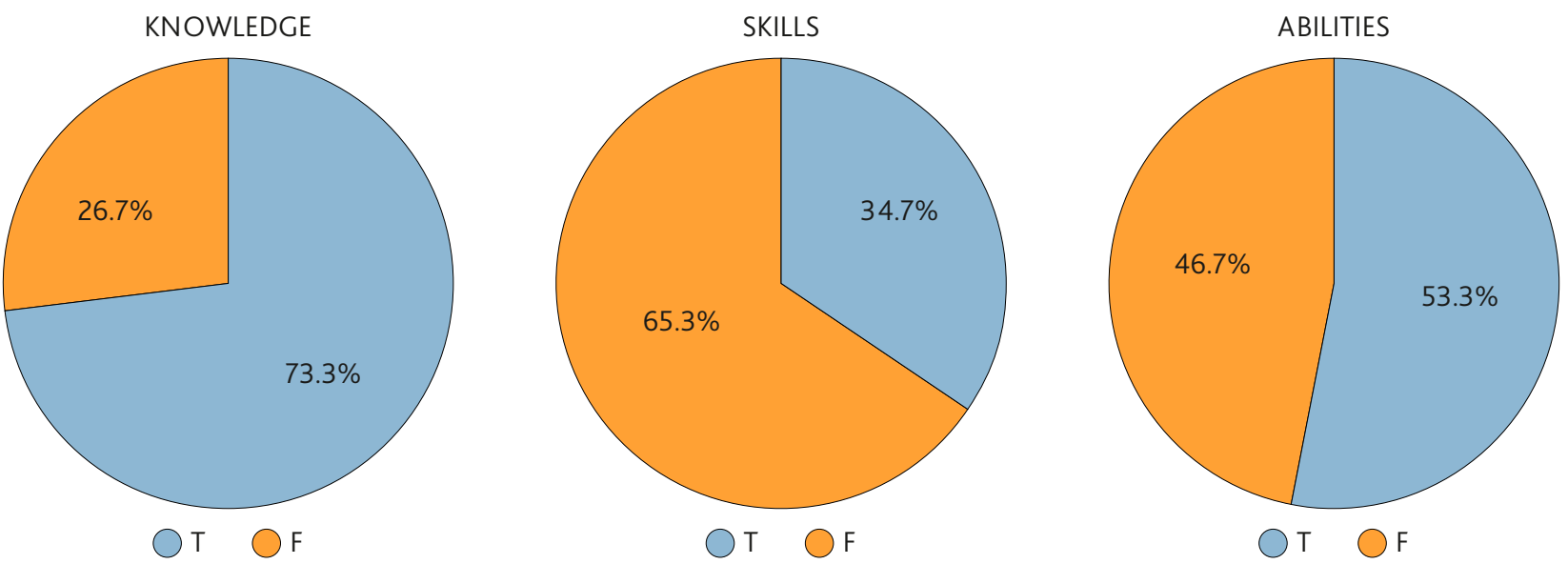

Figures 5, 6 and 7. Graphical view of acquired knowledge, skills and abilities with correct and incorrect answers when using the modern work method 
According to Figure 8, it is noted that the correct students' answers to questions regarding knowledge acquisition were equal in both lessons, provided that students achieved better results during the modern method (73.3\%). The traditional method with application of the principle of intuition and science provided better results regarding skills and abilities acquisition.

As a conclusion, it can be stated that students showed better results by application of traditional teaching carried out through frontal method with emphasizing didactic principle of intuition and science. On the other hand, only some partial goals can be achieved through active participation teaching, but not the majority of important educational goals. This statement comes from the fact that active teach-

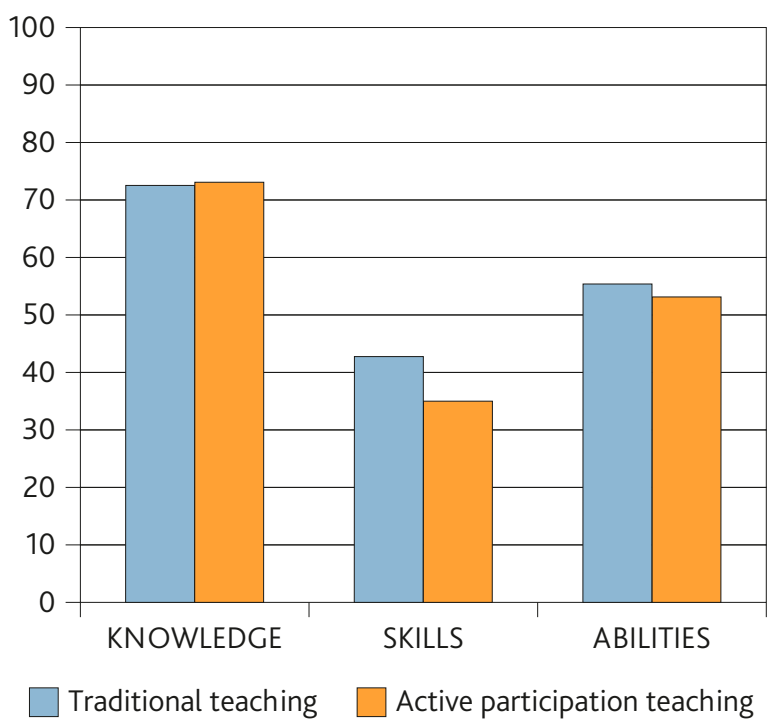

Figure 8. Comparative view of acquired knowledge, skills and abilities in lessons (in \%)

ing cannot be reduced to group work only, but it has to be based on cooperative learning as one of the key methods in an active participation school. Furthermore, students in our schools are used to the traditional method, resulting in showing better results with this method (Ivić, et al., 2001b). It should also be acknowledged that peer students differ from each other in physical, emotional and conotive traits, especially in degree of education, development of work habits and learning motivation. Modern lessons should fit individual, and not just age characteristics of students, wherein the teacher should deal with the abilities of every student and distance the lessons from the "average student's" demands. One of the possible ways of overcoming these problems in geography lessons could be the application of differentiated instruction method, as well as the application of the principle of individualised teaching (Milošević, 2010). In this way, didactic activities would be modified for every student, taking into account their individual abilities.

\section{Results of correlation of test answers for examining competencies}

The test results for examining acquired competencies in students of $2^{\text {nd }}$ year of grammar school were compared with the Pearson Correlation Coefficient. A special correlation for knowledge was carried out, as well as for skills and for abilities. The obtained correlation values are shown in Table 3.

Table 3. Correlation of test answers for both work methods

\begin{tabular}{|l|c|l|}
\hline Competencies & $\begin{array}{c}\text { Correlation } \\
\text { result }(r)\end{array}$ & $\begin{array}{l}\text { Correlation } \\
\text { degree }\end{array}$ \\
\hline KNOWLEDGE & 0.78 & High correlation \\
\hline SKILLS & 0.86 & High correlation \\
\hline ABILITIES & 0.44 & Moderate correlation \\
\hline
\end{tabular}

From this table, and according to the interpretation of the Pearson Correlation Coefficient (r) shown in the paper, it is noted that the knowledge correlation between the two tests is high, which is also the case with skills, while the abilities correlation is moderate.

When it comes to knowledge, students did the test significantly better during lessons that were carried out through active participation, group work and emphasising didactic principles of interesting and attractiveness and conscious activities of students. When skills are compared, it can be concluded that students achieved better results by application of the traditional method with emphasising principle of intuition and science. The same conclusion can also be drawn when reviewing results for abilities. Students performed better in tests during lessons with the traditional method, by application of the frontal method.

According to the obtained correlations, it is noted that, for a quality acquisition of complete curriculum material, it is more suitable for students to have lessons where didactic principle of intuition and science are emphasised.

\section{Conclusion}

By analysing the results shown here, and based on performing experimental lessons, it can be concluded that students acquired educational content in a greater amount during traditional lessons. The lessons were performed with frontal method and by emphasising didactic principle of intuition and science during interpretation of social-geographic contents of specific parts of the world (Europe) in the $2^{\text {nd }}$ year of grammar school.

Students may find it more interesting when a lesson is designed in an unusual and modern way, but the results show that for acquisition of educational content, as well as of knowledge, skills and abilities, it is better to apply the traditional method with the use of 
didactic principle of intuition and science. Therefore, we can conclude that, the hypothesis that application of selected didactic principles during interpretation of specific teaching units gives positive results in regards to students' acquisition of knowledge, skills and abilities was confirmed to a great extent. When it comes to examining students' motivation in terms of participation, activities and learning/acquiring specific geographical contents, the results show that students prefer when the teacher organises a lesson in an interesting way. With the traditional method, a small number of students stated that they are not pleased with the level of activities, while with the modern method, a small number of students answered that they prefer lessons where their participation is not necessary. Therefore, it is noted that it is more interesting and easier for students to acquire knowledge when the teacher designs a lesson in an interesting and attractive way, by using pictures, showing multimedia contents, PowerPoint presentations, etc. Based on the content presented, it is concluded that students prefer lessons performed in an interesting way where they will be more motivated than during lessons where only the teacher presents the content during the frontal method.

Since students' abilities differ, it is necessary to search for teaching methods which take into consideration the differences between students in the best way, in regards to a different level of achievements and aspirations. One of the basic goals of geography lessons is for students to permanently acquire the knowledge, skills and abilities, to implement them in new teaching and real life situations, and, in that way, to minimise the process of forgetting.

It should be taken into account that peer students differ in physical, emotional and conotive characteristics, and especially in level of education, development of work habits and learning motivation. One of the possible ways of overcoming these problems in teaching geography could be the application of the principle of individualised teaching, that is, the differentiated instruction method and cooperative learning as one of the key teaching methods in an active participation school.

Application of different didactic principles, methods, as well as teaching means, creates an atmosphere where students with different abilities and affinities achieve better results during lessons regardless of whether physical-geographic, social-economic or regional-geographic educational contents are in question.

\section{References}

Anderson, J. 2013. Active learning through student film: a case study of cultural geography. Journal of Geography in Higher Education 37, 3, 385-398

Babić-Kekez, S., Tasić, I. 2012. Didactics, University of Novi Sad. (in Serbian)

Borić, E., Škugor, A. 2012. Achieving Students' Competencies Through Research-Based Outdoor Science Teaching. Croatian Journal of Education 16, 1, 149-164

Dubljanin, S. 2010. The Need for a new Interpretation of the Didactic Principles, Pedagogy 65, 1, 169-172 (in Serbian)

Fletcher, S. 2005. Review of 'Engaging Students in Active Learning: Case Studies in Geography, Environment and Related Disciplines'. Journal of Geography in Higher Education 29, 2, 313-315

Frumos, F. 2008. Didactica: Fundaments and cognitive developments. Iaşi: Polirom Publishing House. (in Romanian)

Hamann, B. 2007. Australia in German Geography Textbooks for Middle Schools. International Research in Geographical \& Environmental Education $16,2,135-146$

Đukičin, S., Ivanović Bibić, Lj., Lukić, T., Dubovina, Z. 2014. Analysis of the utilization of supplementary illustrations - an example of the selected teaching units from the fifth grade geography textbook (Republic of Serbia). Geographica Pannonica 18, 4, 89-85

Živković, Lj., Jovanović, S. 2008. Active Learning in Geography Instruction-class model. Collection of Papers - Faculty of Geography at the University of Belgrade 56, 257- 268 (in Serbian)

Ivanović, Lj., Ivkov, A. 2007. The Importance of applying illustrative-demonstrative Methods in Geography Teaching. Zbornik radova ", ${ }^{\text {st }}$ Congress of Serbian Geographers". Bulletin of the Serbian Geographical Society 3, 1251-1258 (in Serbian)

Ivkov, A. 2002. Teaching Geography in Primary and Secondary Schools, a Guide for Students and Seachers. University of Novi Sad, Faculty of Science, Department of Geography, Tourism and Hotel Management, Novi Sad. (in Serbian)

Ivkov, A. 2003. Active Methods in Geography Teaching - way towards more qualitative education. Researches Review of the Department of Geography, Tourism and Hotel Management 32, 91-98 (in Serbian)

Ivkov-Džigurski, A., Ivanović, Lj., Pašić, M. 2009. Possibilities of Computer Application in Modern Geography Teaching Process. Bulletin of the Serbian Geographical Society 89, 1, 139-151 (in Serbian)

Ivić, I., Pešikan, A., Antić, S. 2001a. Active Learning. Institute of Psychology, Belgrade (in Serbian) 
Ivić, I., Pešikan, A., Antić, S. 2001b. Active Learning II. Institute of Psychology, Belgrade (in Serbian)

Kovačević, V., Mladenović-Kljajić, B. 2014. Geography for $2^{\text {nd }}$ Year of Grammar School. Klett, Belgrade (in Serbian)

Likert, R. 1932. A Technique for the Measurement of Attitudes. Archives of Psychology 140, 1-55

Marius-Costel, E. 2010. The didactic principles and their applications in the didactic activity. Sino-US English Teaching 7, 9, 24-34

Marić, Đ., Krunić, D. 2003. The System of Didactic Principles in the Teaching of Geography. Globus, 28, 93-108 (in Serbian)

Milošević, D. 2010. Application of Differentiated Form of Teachning in Geography in sixth grade. Researches Review of the Department of Geography, Tourism and Hotel Management 39, 36-51 (in Serbian)

Romelić, J. 2004. Methodology of Teaching Geography. University of Novi Sad, Faculty of Science, Department of Geography, Tourism and Hotel Management, Novi Sad (in Serbian)

Romelić, J., Ivanović, Lj. 2011. The Didactic Principles in the Teaching of Geography. University of Novi Sad, Faculty of Science, Department of Geography, Tourism and Hotel Management, Novi Sad (in Serbian)
Scheyvens, R., Griffin, A., Jocoy, C., Liu, Y., Bradford, M. 2008. Experimenting with Active Learning in Geography: Dispelling the Myths that Perpetuate Resistance. Journal of Geography in Higher Education 32, 1, 51-69

Stojković, M. 2008. Statistics Methods in Tourism. University of Novi Sad, Faculty of Science, Department of Geography, Tourism and Hotel Management, Novi Sad, 232 pp. (in Serbian)

Turjačanin V., Čekrlija Đ., Kovačević, P., Opačić, G. 2006. Basic Statistical Methods and Techniques in SPSS - Application of SPSS in Social Sciences. Center for Cultural and Social Repair, Banja Luka (in Serbian)

Tracana, R. B., Carvalho, G., Ferreira, C., Ferreira, M. E. 2008. Analysing the Theme of Pollution in Portuguese Geography and Biology Textbooks. International Research in Geographical \& Environmental Education 17, 3, 199-211

Yasar, O., Seremet, M. 2007. A Comparative Analysis Regarding Pictures Included in Secondary School Geography Textbooks Taught in Turkey. International Research in Geographical \& Environmental Education 16, 2, 157-187 